Case Reports

\title{
Bending Stress and Deflection Analysis of Meshing Spur Gear Tooth during the Single Tooth Contact with Finite Element Method and Determination of the Bending Stiffness
}

\author{
Antonios D. Tsolakis, Konstantinos G. Raptis and Maria D. Margaritou \\ Department of Mechanical Engineering, School of Applied Sciences and Technology, \\ Piraeus University of Applied Sciences, 250 Thivon and P. Ralli, 12244, Egaleo, Greece
}

\author{
Article history \\ Received: 03-11-2015 \\ Revised: $18-05-2017$ \\ Accepted: 02-06-2017 \\ Corresponding Author: \\ Antonios D. Tsolakis \\ Department of Mechanical \\ Engineering, School of Applied \\ Sciences and Technology, \\ Piraeus University of Applied \\ Sciences, 250 Thivon and P. \\ Ralli, 12244, Egaleo, Greece \\ Email: adtsolakis@gmail.com
}

\begin{abstract}
Purpose of this study is the study of loading and contact problems encountered at rotating machine elements and especially at tooth gears. Tooth gears are some of the most commonly used mechanical components for rotary motion and power transmission. This fact proves the necessity for improved reliability and enhanced service life, which requires precise and clear knowledge of the stress field at gear tooth. This study investigates three different study cases of the stresses occurring during the single tooth meshing, regarding the gear module, power rating and number of teeth as variable parameters. Using finite elements analysis, the stresses and deflections on discrete points of contact are derived. Finally from the finite elements analysis results calculated the peripherical bending stiffness of the loaded tooth. From FEM analysis and analytical calculation the magnitudes of root stresses, contact displacement and peripherical bending stiffness, during the single tooth contact, are presented with graphs versus the height of the contact to the total tooth height ratio. During the single tooth contact the values of the Equivalent and 1st principal stress at the addendum of the tooth, the bending deflection and the peripherical bending stiffness at the point of contact are proportional to the height of the contact in respect of the total tooth height.
\end{abstract}

Keywords: Gears, Gears Tooth, Highest Point of Single Tooth Contact (HPSTC), Bending Stresses, Bending Deflection, Finite Element Method (FEM)

\section{Introduction}

Most mechanical systems including gear sets are sensitive to operating conditions such as excessive applied torque, bad lubrication and manufacturing or installation problems. When the tooth surfaces are subjected to excessive stress conditions, failure of the tooth surface may occur. This can cause removal and plastic deformation of the contacting tooth surfaces and fatigue crack apparition. Many works have been carried out to calculate this stiffness. Finite Elements Models (FEM) are the most popular tools used to do this. However, analytical methods showed good results in calculating tooth stiffness. They offer satisfying results, good agreements compared with FEM and reduced computation time (Fakher et al., 2009).
First systematic attempt to calculate the position of critically stressed point is attributed to Lewis (1882), who considered that the inscribed isosceles parabola tangent to the dedendum of the tooth flank defines the critically stressed point which is located at the point of tangency at the side which is loaded by tensile stresses.

Methods, such as AGMA standard and DIN (Kawalec et al., 2006), Heywood's semi-empirical method (Heywood, 1962) and Dolan and Broghamer's (1942) empirical formula, can be found on references and are recommended for the determination of the precise stress level caused by the phenomenon of the stress concentration at gear tooth root.

According to method proposed by DIN 3990 (1987) and ISO 6336:3 (1996), standards, the bending stresses calculation at gear tooth root is based on the concept of 
“30 ${ }^{\circ} \mathrm{C}$ tangent", (Heywood, 1962), which proves to be a disadvantage. Thus, this method is quite approximate and should not be applied to the design of high load gearings.

Heywood's method (Heywood, 1962), is applied for the determination of maximum real stress at critically stressed point at the root of a stubby beam with constant width. This method was later modified in order to make more precise prediction of the critical point which is located at a lower position from then on.

\section{Materials and Methods}

The previously mentioned methods of maximum stress calculation at gear tooth root will not be applied to the present study, because the determination of the necessary geometric features, especially at the critical region of gear tooth fillet which requires more precise computations, is a time-consuming procedure. Instead, the applied method assumes that the maximum load during gear tooth meshing is applied to the Highest Point of Single Tooth Contact (HPSTC), (Spitas et al., 2005; Raptis et al., 2010).

\section{Gear Tooth Bending Stress Calculation According to the Gearing Theory}

The gear tooth bending stress calculations are made separately for pinion and meshing gear tooth.
Assuming the gear tooth is a stubby cantilever beam, we calculate the stresses at gear tooth root, which are growing by the load $F_{n}$ application. If we resolve load $F_{n}$ into its components, there are the tangential component and the radial component. The first one, assuming that it's a transversal load, bends the gear tooth causing bending and shear stresses while the second one, causes compressive stress. That means that there are three kind of stresses which are applying at gear tooth root. These three kinds of stresses are, the bending stress, the compressing stress and the shear stress, as seen at Fig. 1.

Since the overlap coefficient (or contact ratio) is greater than $1(\varepsilon>1)$, it means that for a certain period of the implementation, a second pair of teeth comes into engagement before the first pair breaks contact. Therefore, load $F_{n}$ is acting on both pairs of teeth. As seen at Fig. 2:

- $\quad$ A is the point of contact at pinion root. From this point contact begins, so load $F_{n}$ is distributed at two pairs of gear teeth

- $\quad \mathrm{B}$ is the internal single point of contact, according to pinion. The second pair of gear tooth breaks contact on point $E$. That means that only a single tooth pair is in contact subjected to the total load $F_{n}$ at point B

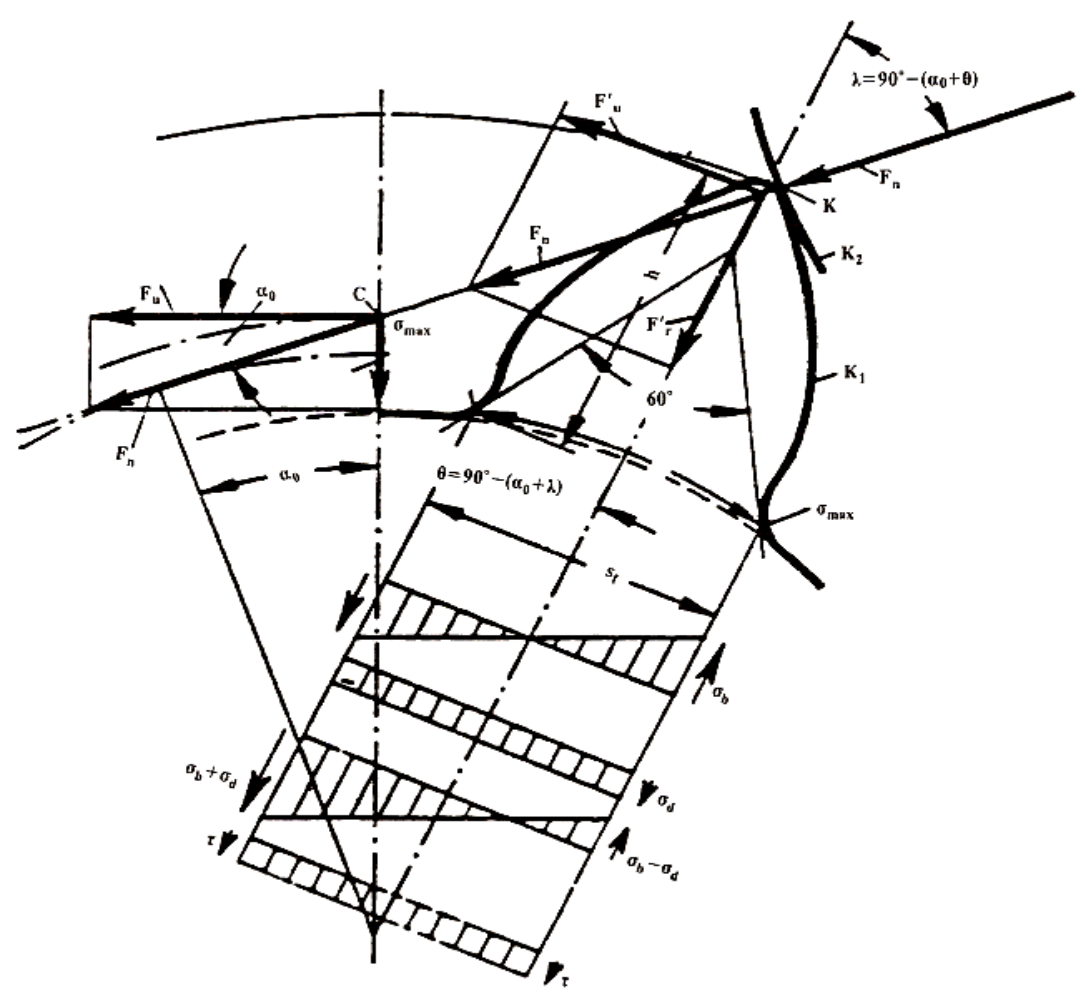

Fig. 1. Gear tooth flank loading 


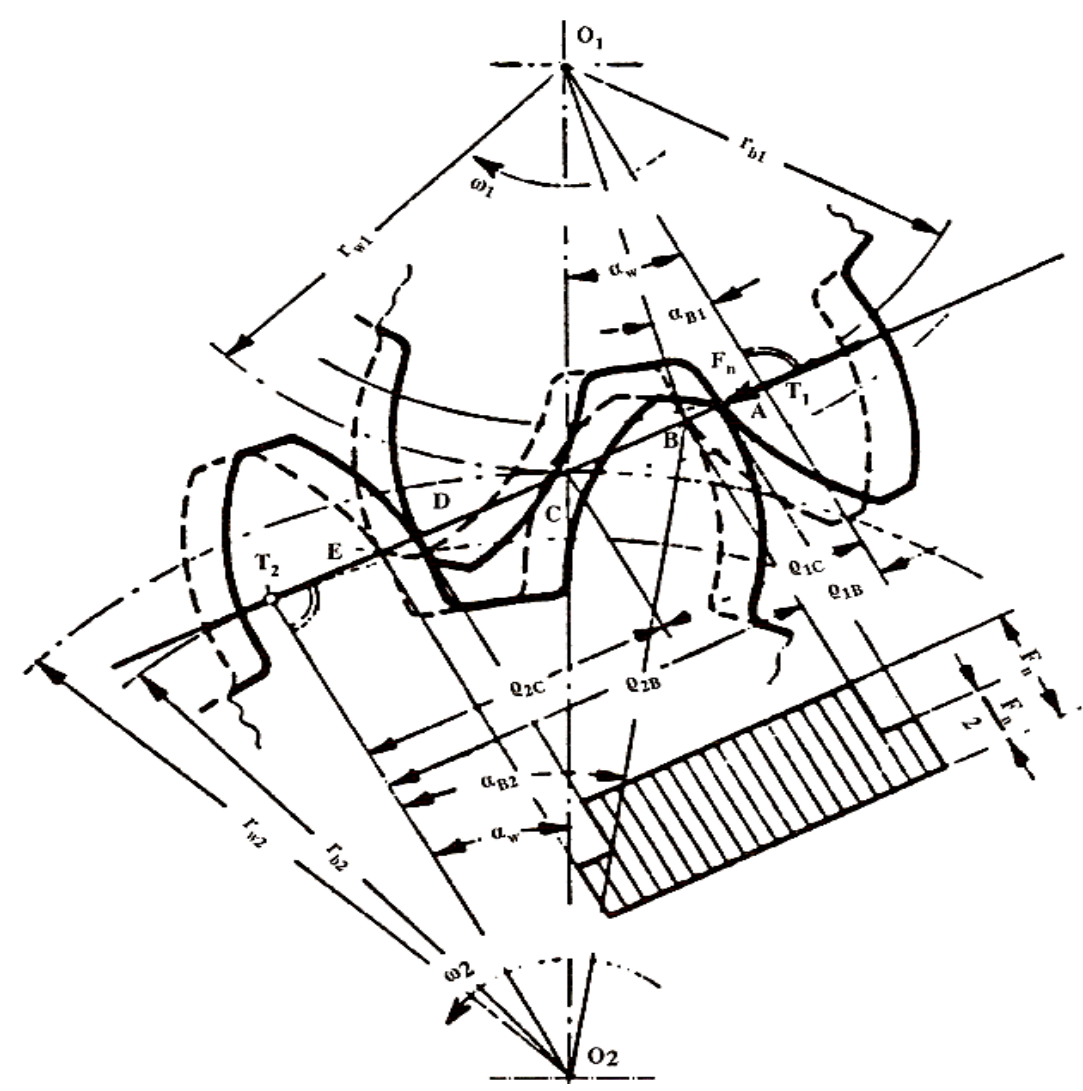

Fig. 2. Single points of contact at external tooth gear

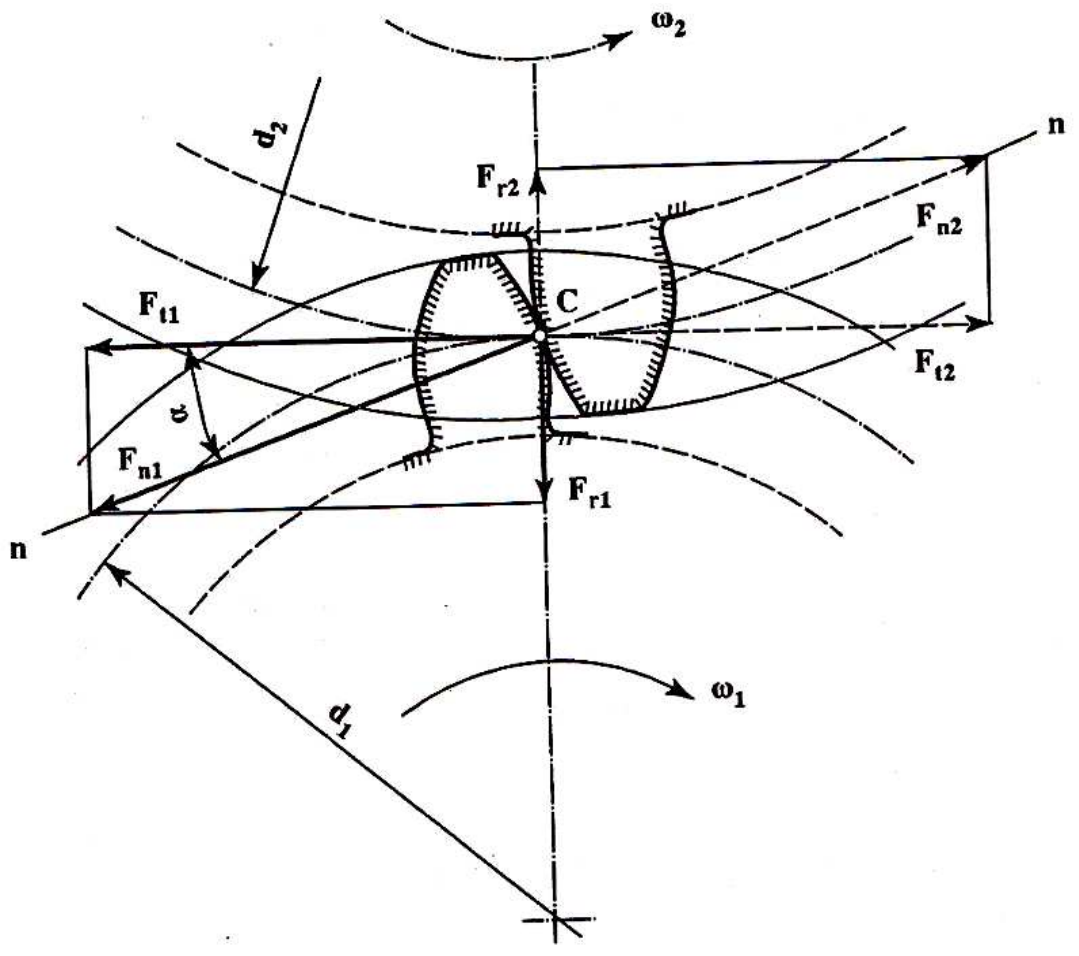

Fig. 3. Loads at spur gear teeth 


\section{Loads Applied at Pair of Gear Teeth}

Assuming that only one pair of spur gear teeth is on contact during a gear tooth meshing, then gear tooth 1 profile which transmits motion, stresses gear tooth 2 profile which takes motion. Transversal load $F_{n}$ which applies at the gear teeth point of contact, coincides (if we put that point on the involute of the tooth curve) with the tooth contact path n-n, which crosses the pitch point $C$ (Fig. 3). We assume that load $F_{n}$ applies at the middle of the gear tooth length $b$.

Load $F_{n 1}$ applies at tooth profile following a fatigue failure line direction. Ignoring the fact of friction, load $F_{n 2}$, which is numerical equivalent with load $F_{n 1}$ but in opposite sense, set on motion gear tooth 2 , following also a fatigue failure direction.

Loads $F_{n 1}$ and $F_{n 2}$, resolve giving radial components $F_{r 1}, F_{r 2}$ and tangential components $F_{t 1}, F_{t 2}$ which transmit torque from gear tooth 1 to gear tooth 2 .

The torque $M_{t}$ at gear 1 with a pitch diameter $d_{1}$, is:

$M_{t}=\frac{F_{t 1} \cdot d_{1}}{2000}(N \cdot m)$

The tangential load is calculated by using the equation:

$F_{t 1}=\frac{2000 \cdot M_{t}}{d_{1}}(N)$

The transversal load is calculated by using the equation:

$F_{n 1}=\frac{F_{t 1}}{\cos \alpha}(N)$

The radial load is calculated by using the equation:

$F_{r 1}=F_{t 1} \cdot \tan \alpha(N)$

where, $\alpha$ is pressure angle, is the angle between the path contact and the common tangent of the two pitch circles at pitch point $C$.

\section{Formulas for Calculating the Gear Tooth Strength}

The section $S_{f}$, to the dedendum of the tooth flank (Fig. 1), which affects the calculating formulas of gear tooth strength, can be calculated by using the concept of " $30^{\circ} \mathrm{C}$ tangent" (Heywood, 1962), or the general theory. The bending stress calculation at gear tooth root is made by using the following formula:

$\sigma_{F}=\frac{F_{t}}{b \cdot m} \cdot Y_{F} \cdot Y_{\varepsilon} \cdot K_{F \alpha} \leq \sigma_{F \varepsilon \pi}$
The transversal load $F_{u}$ is calculated by using the following formula:

$F_{u}=\frac{2 \cdot M_{t}}{d_{o}}$

The torque $M_{t}$ is calculated by using the following formula:

$M_{t}=\frac{P}{2 \cdot \pi \cdot n}$

The gear tooth width is calculated by using the following formula:

$b=m \cdot \lambda$

Where:

$\lambda=\mathrm{A}$ direction factor which depends on the gear tooth material quality and the bear way

$Y_{F}=$ A profile factor which depends on the shift and the number of gear teeth

$Y_{\varepsilon}=$ An overlap coefficient

$K_{F \alpha}=$ A factor of distribution load which depends on the gear tooth material quality

\section{Highest Point of Single Tooth Contact (HPSTC) During Tooth Meshing}

It is proven that the normal load $P_{N}$ on a gear tooth is not maximum when applied at the addendum circle. As shown in Fig. 4 during gear tooth meshing, from point A where tooth contact begins to point $A^{\prime}$ of tooth contact path and from point B' to point $\mathrm{B}$, where tooth contact completes, two pairs of teeth ate in contact simultaneously. On the other hand, between points $\mathrm{A}^{\prime}$ and $\mathrm{B}^{\prime}$ only a single tooth pair is in contact subjected to the total load.

It can, thus, be assumed that the worst loading condition for a tooth of gear 1 does not occur when the load is applied to the highest addendum point (point B), because the total load is distributed to two pairs of gear teeth at this point, but when applied to point B' of contact path where only a single pair or gear teeth is meshing, (Niemann, 1982; Spitas et al., 2005; Tsolakis and Raptis, 2011).

Point A' is defined The Lowest Point of Single Tooth Contact (LPSTC) and point B' is the Highest Point of Single Tooth Contact (HPSTC) for gear 1. That is, during portion A'B' of the contact path only a single tooth of each gear is loaded, whereas during portions $\mathrm{AA}^{\prime}$ and $\mathrm{BB}$ ' the load is distributed to the teeth of each gear. Thus, we can infer that the maximum gear tooth loading occurs at a point on part A'B' of the contact path. 


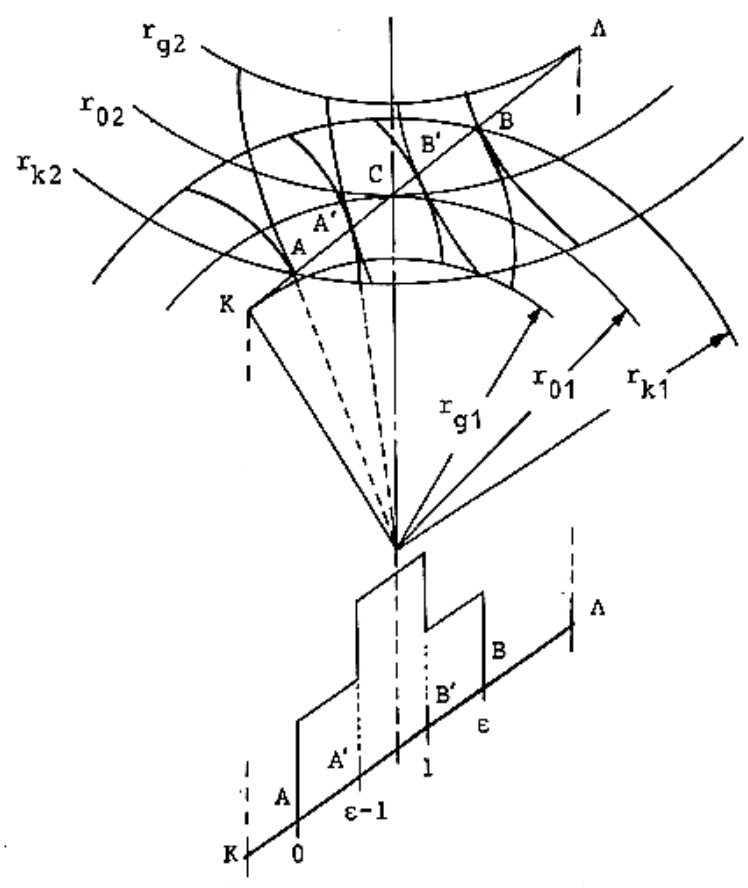

Fig. 4. (a) Gear teeth profiles of a gear transmission stage (b) Position of tooth load variation

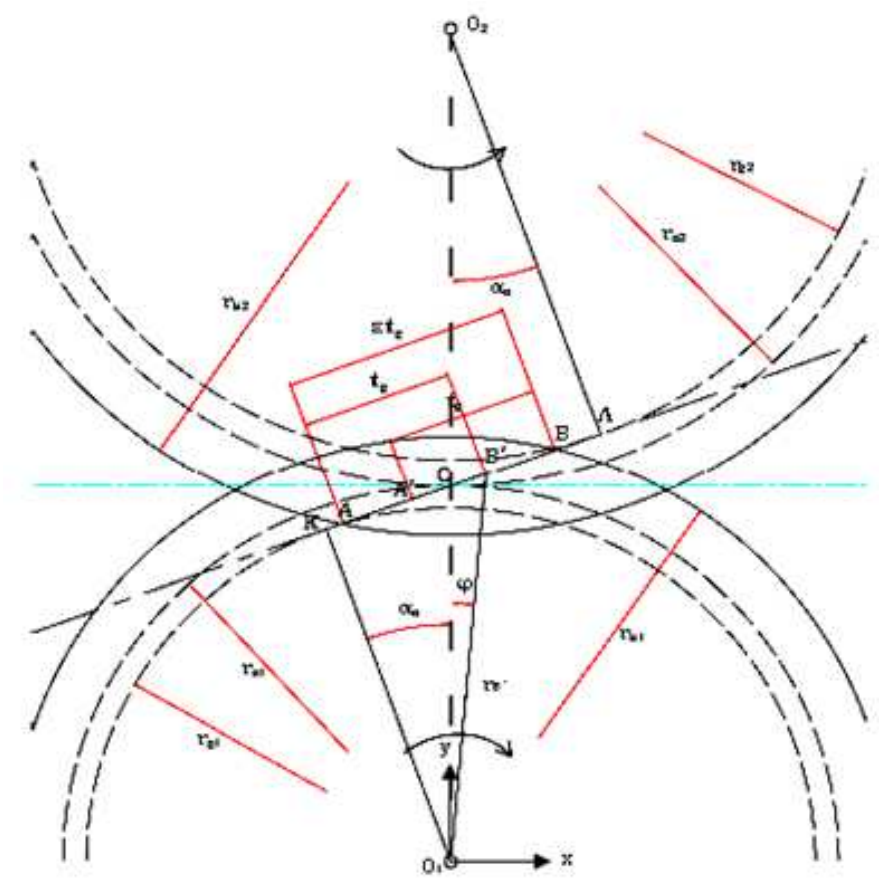

Fig. 5. Geometric determination of HPSTC

Table 1. Analytical data for each gear

\begin{tabular}{llclll}
\hline Gear No & $z_{1}=z_{2}$ & $\mathrm{~m}(\mathrm{~mm})$ & $\mathrm{P}(\mathrm{KW})$ & $\mathrm{n}(\mathrm{rpm})$ & $\mathrm{M}_{\mathrm{t}}(\mathrm{Nm})$ \\
\hline 1 & 18 & 6 & 20 & 1250 & 131,78 \\
2 & 20 & 10 & 20 & 1450 & 131,78 \\
3 & 22 & 8 & 20 & 1250 & 131,78 \\
\hline
\end{tabular}


Determination of the point of maximum stresses during gear meshing (Fig. 4), (Niemann, 1960; Spitas and Spitas, 2007; Costopoulos and Spitas, 2009), is as follows:

$$
\begin{aligned}
& A B=\varepsilon \cdot t_{g}=A C+A B \\
& A C=\sqrt{\left(r_{02}+m\right)^{2}-r_{02}^{2}-\cdot \cos ^{2} \alpha_{0}}-r_{02} \cdot \sin \alpha_{0} \\
& B C=\sqrt{\left(r_{01}+m\right)^{2}-r_{01}^{2}-\cdot \cos ^{2} \alpha_{0}}-r_{01} \cdot \sin \alpha_{0}
\end{aligned}
$$

Substituting Equation 10 and 11 to Equation 9 results Equation 12:

$$
\begin{aligned}
& A B \sqrt{\left(r_{02}+m\right)^{2}-r_{02}^{2} \cdot \cos ^{2} \alpha_{0}} \\
& +\sqrt{\left(\left(r_{01}+m\right)^{2}-r_{01}^{2} \cdot \cos ^{2} \alpha_{0}\right)}-\left(r_{01}+t_{02}\right) \cdot \sin \alpha_{0}
\end{aligned}
$$

HPSTC is located at point B'. During parts AA' and BB' of the contact path, load is transmitted through two pairs of gear teeth, while during part A'B' only a single pair of gear teeth is subjected to the total load. The lengths of parts $\mathrm{AB}^{\prime}$ and $\mathrm{A}^{\prime} \mathrm{B}$ equal the gear circular pitch, $t_{g}$, at the base circle. Thus, position of HSPTC is determined according to Fig. 5 as follows:

$$
\begin{aligned}
& A C=\sqrt{\left(r_{02}+m\right)^{2}-r_{02}^{2} \cdot \cos ^{2} \alpha_{0}}-r_{02} \cdot \sin \alpha_{0} \\
& C B^{\prime}=A B^{\prime}-A C=t_{g}-A C=\pi \cdot m \cdot \cos \alpha_{0}-A C
\end{aligned}
$$

Using triangle $O_{1} B^{\prime} C$, (Spitas et al., 2005; Spitas and Spitas, 2007; Raptis et al., 2012), radius $r B^{\prime}$ can be calculated according to the following Equation:

$$
r_{B^{\prime}}=\sqrt{r_{01}^{2}+C B^{\prime 2}-2 \cdot r_{01} \cdot C B^{\prime} \cdot \cos \left(\alpha_{0}+90^{\circ}\right)}
$$

Cartesians coordinates of point $H$ are: $(x, y)=(r B$ $\sin \varphi, r B \cos \varphi)$

\section{Results and Discussion}

\section{Bending Stress Finite Element Analysis}

For the purposes of this investigation, computed Finite Element Analysis was used to simulate the loading of different gear teeth (Table 1), with one-tooth models fixed at their boundary (Fig. 6-8). For each tooth model, 11 loaded models have been analyzed.

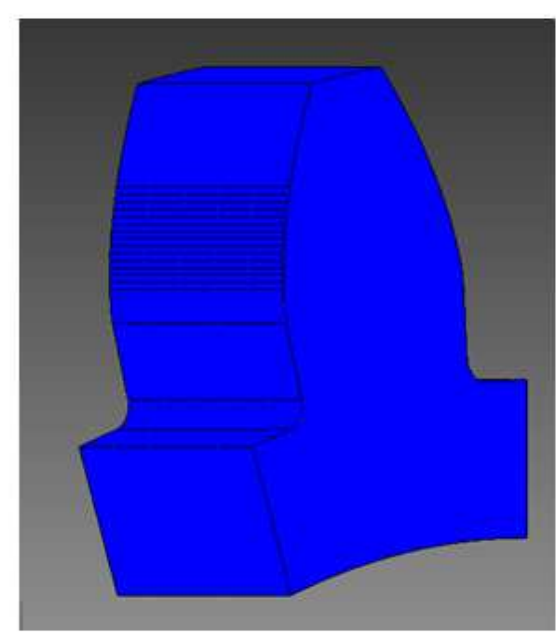

Fig. 6. Solid model structure

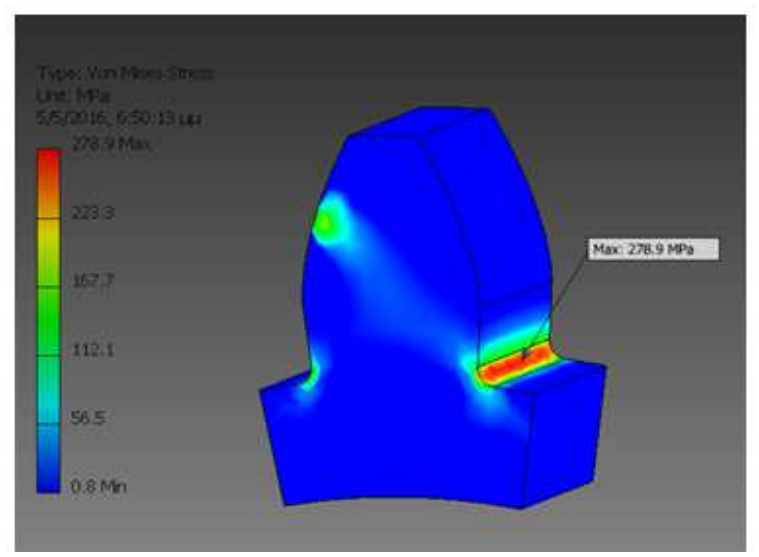

Fig. 7. Equivalent Stress at the HPSTC for $\mathrm{m}=6 \mathrm{~mm}$ model

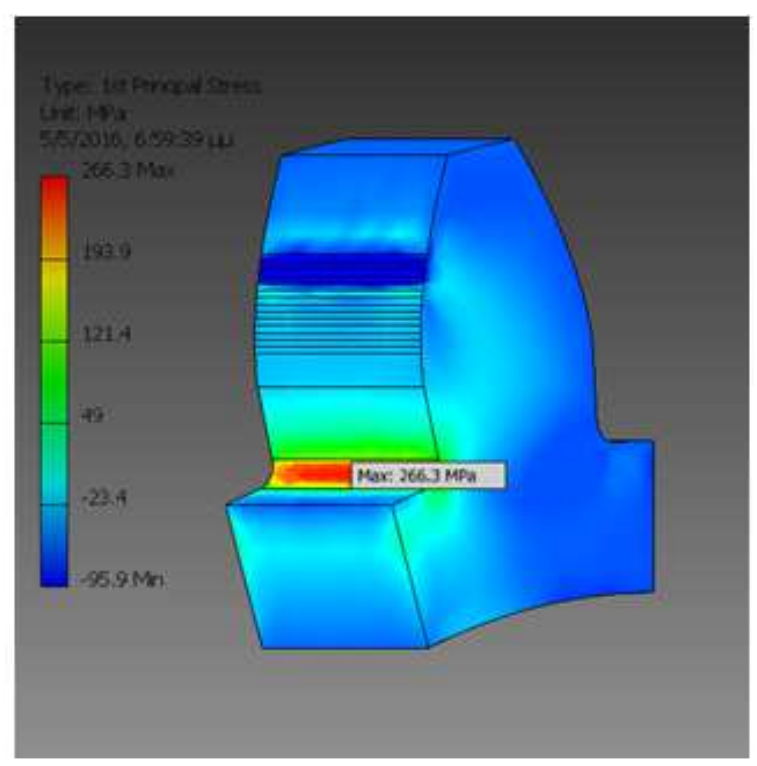

Fig. 8. 1st Principal Stress at the HPSTC for $\mathrm{m}=6 \mathrm{~mm}$ model 


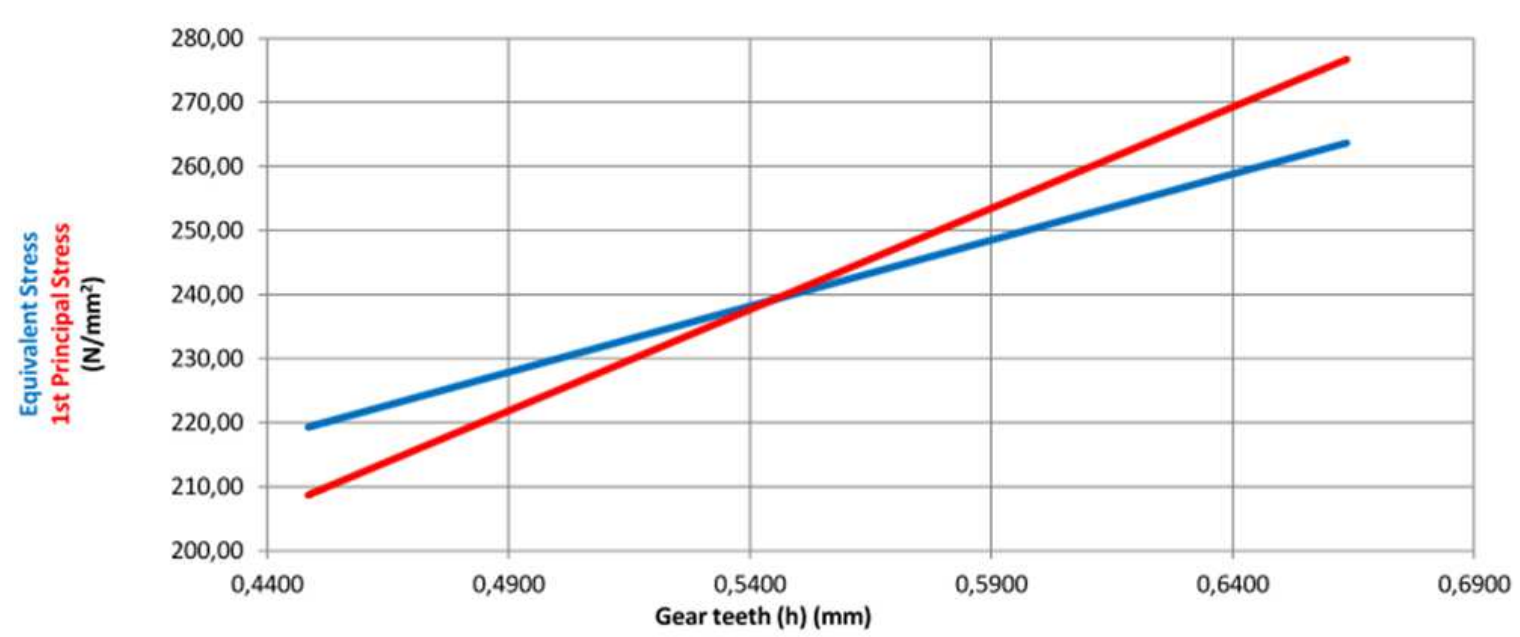

Fig. 9. Diagram between gear teeth $\mathrm{h}$ ratio and Equivalent -1 st Principal Stress $(\mathrm{m}=6$ and $\mathrm{z}=18)$; Gear $2:\left(\mathrm{z}_{1}=\mathrm{z}_{2}=20, \mathrm{~m}=10\right)$

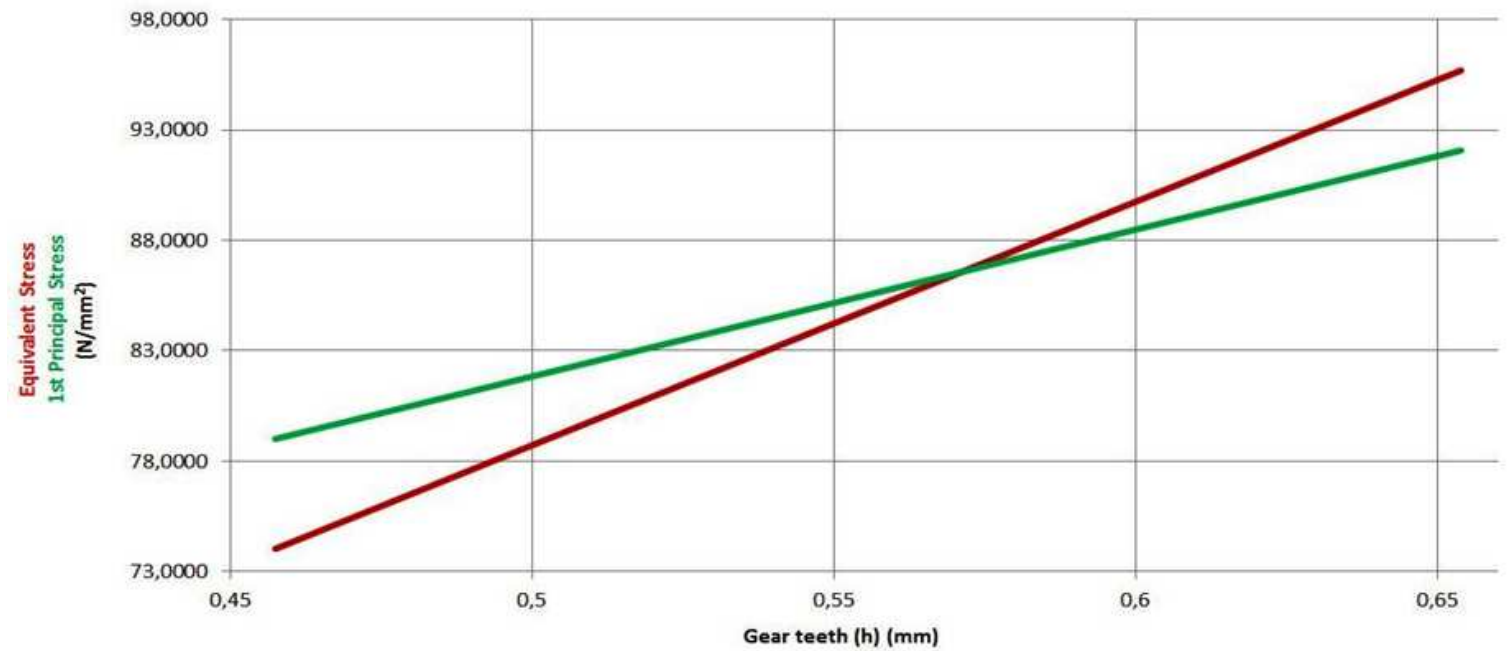

Fig. 10. Diagram between gear teeth $\mathrm{h}$ ratio and Equivalent -1 st Principal Stress $(\mathrm{m}=8$ and $\mathrm{z}=22)$

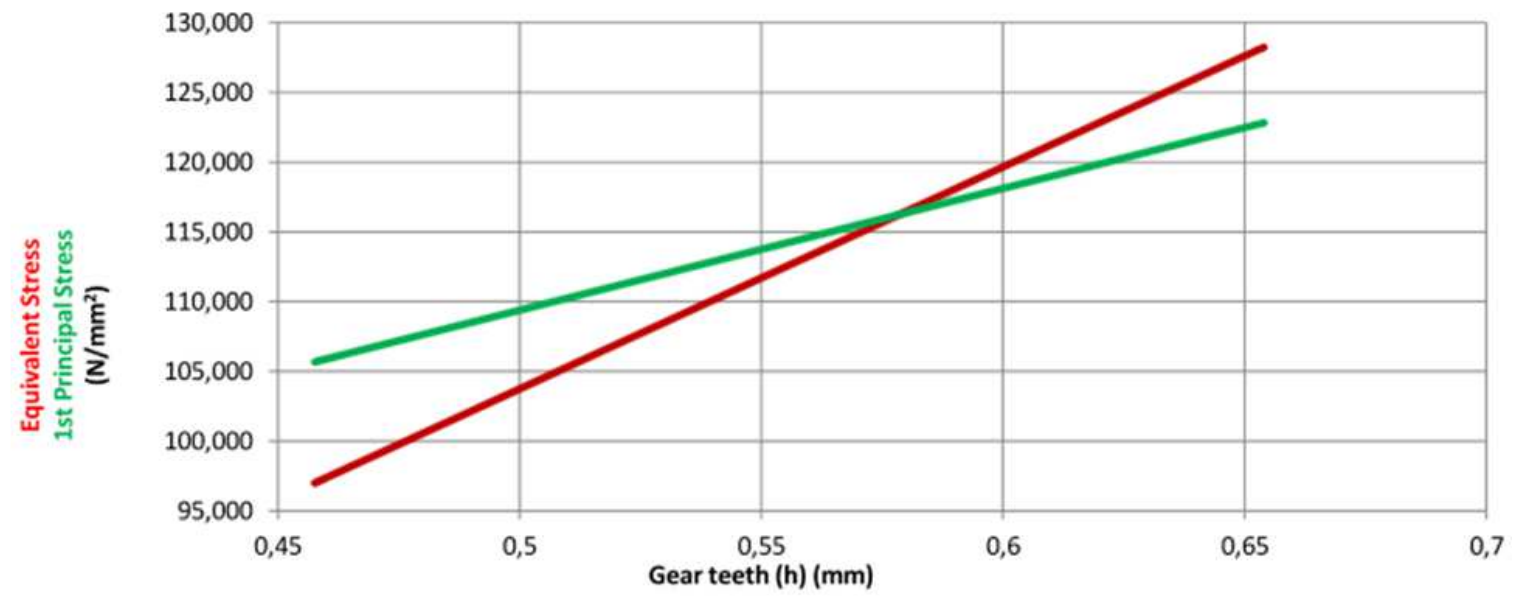

Fig. 11. Diagram between gear teeth $\mathrm{h}$ ratio and Equivalent -1 st Principal Stress $(\mathrm{m}=10$ and $\mathrm{z}=20)$ 


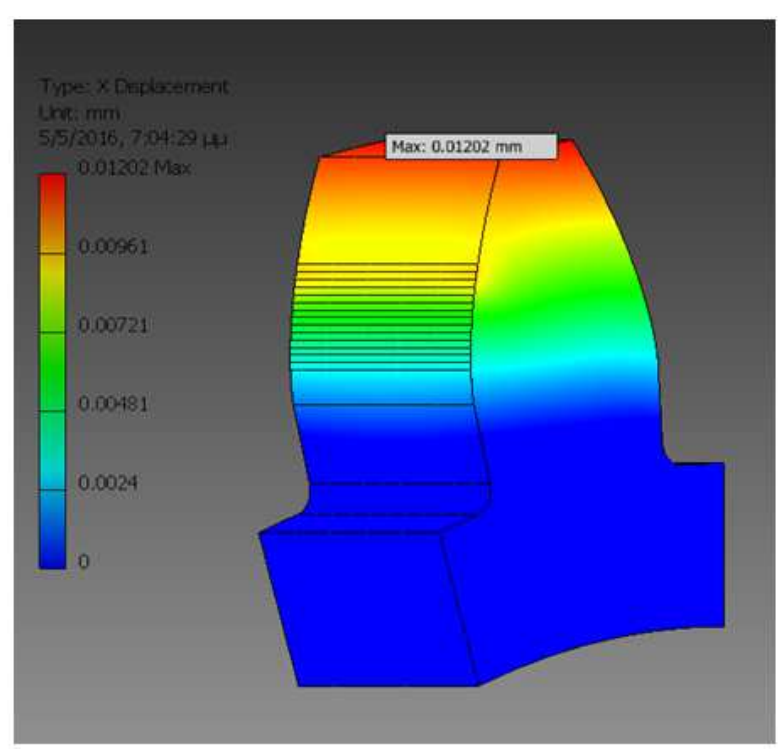

Fig. 12. $\mathrm{x}$-Displacement at the HPSTC for $\mathrm{m}=6 \mathrm{~mm}$ model

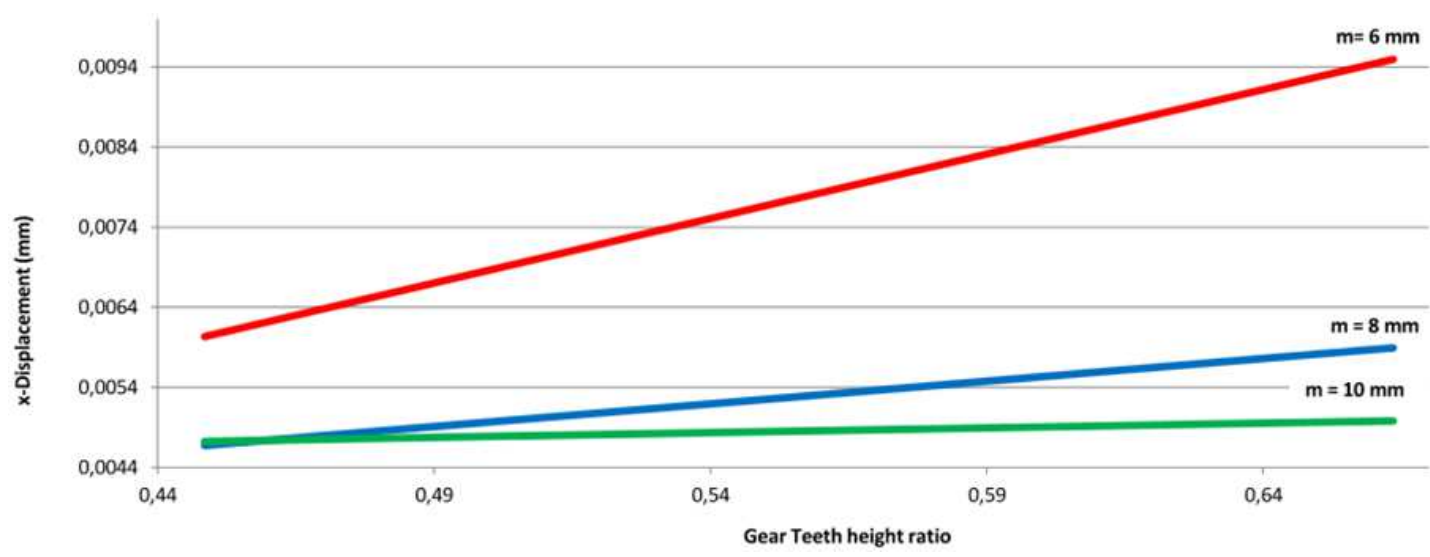

Fig. 13. Diagram between gear teeth height ratio and $\mathrm{x}$ displacement $(\mathrm{mm})$

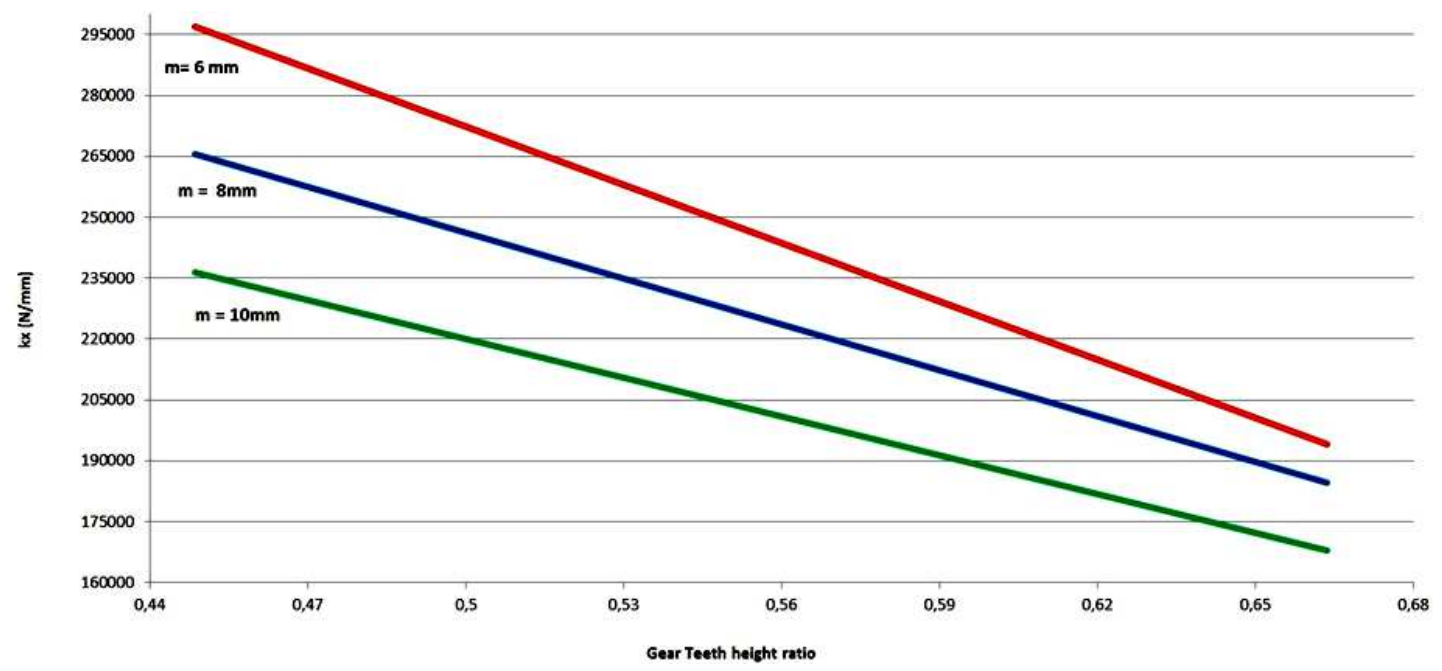

Fig. 14. Diagram between Gear Teeth Height ratio and $\mathrm{Kx}(\mathrm{N} / \mathrm{mm})$ 
Antonios D. Tsolakis et al. / American Journal of Engineering and Applied Sciences 2017, 10 (2): 540.550 DOI: 10.3844/ajeassp.2017.540.550

\begin{tabular}{|c|c|c|c|c|c|c|}
\hline $\begin{array}{l}\text { Contact distance from } \\
\text { the gear 1center (mm) }\end{array}$ & $\begin{array}{l}\text { Pressure } \\
\text { angle } \alpha^{\circ}\end{array}$ & $\begin{array}{l}\text { Contact distance from } \\
\text { the gear } 2 \text { center }(\mathrm{mm})\end{array}$ & $\begin{array}{l}\text { Tangential } \\
\text { Load Ft }(\mathrm{N})\end{array}$ & $\begin{array}{l}\text { Equivalent } \\
\text { Stress }\left(\mathrm{N} / \mathrm{mm}^{2}\right)\end{array}$ & $\begin{array}{l}1^{\text {st }} \text { Principal } \\
\text { Stress }\left(\mathrm{N} / \mathrm{mm}^{2}\right)\end{array}$ & $\begin{array}{l}\text { Gear Teeth } \\
\text { height ratio }\end{array}$ \\
\hline 52,72 & 15,739 & 55,56 & 2499,6 & 224,00 & 212,50 & 0.4485 \\
\hline 53,00 & 16,794 & 55,28 & 2486,3 & 223,50 & 214,90 & 0.4700 \\
\hline 53,29 & 17,778 & 54,99 & 2473,0 & $226, .60$ & 221,20 & 0.4915 \\
\hline 53,57 & 18,702 & 54,71 & 2459,9 & 232,40 & 227,30 & 0.5130 \\
\hline 53,86 & 19,575 & 54,42 & 2446,9 & 234,30 & 235,60 & 0.5345 \\
\hline 54,14 & 20,403 & 54,14 & 2434,1 & 240,80 & 242,40 & 0.5561 \\
\hline 54,42 & 21,192 & 53,86 & 2421,4 & 243,60 & 247,30 & 0.5776 \\
\hline 54,71 & 21,947 & 53,57 & 2408,8 & 249,70 & 255,90 & 0.5991 \\
\hline 54,99 & 22,670 & 53,29 & 2396,4 & 254,30 & 262,20 & 0.6206 \\
\hline 55,28 & 23,364 & 53,00 & 2384,1 & 260,70 & 271,10 & 0.6421 \\
\hline 55,56 & 24,033 & 52,72 & 2371,9 & 266,30 & 278,90 & 0.6636 \\
\hline
\end{tabular}

Table 3. Parameters and FEA result values for $\mathrm{m}=8 \mathrm{~mm}$ model

\begin{tabular}{lllllll}
\hline $\begin{array}{l}\text { Contact distance from } \\
\text { the gear 1 center }(\mathrm{mm})\end{array}$ & $\begin{array}{l}\text { Pressure } \\
\text { angle } \alpha^{0}\end{array}$ & $\begin{array}{l}\text { Contact distance from } \\
\text { the gear 2 center }(\mathrm{mm})\end{array}$ & $\begin{array}{l}\text { Tangential } \\
\text { Load Ft }(\mathrm{N})\end{array}$ & $\begin{array}{l}\text { Equivalent } \\
\text { Stress }\left(\mathrm{N} / \mathrm{mm}^{2}\right)\end{array}$ & $\begin{array}{l}\text { 1st Principal } \\
\left.\text { Stress (N/mm }{ }^{2}\right)\end{array}$ & $\begin{array}{l}\text { Gear Teeth } \\
\text { height ratio }\end{array}$ \\
\hline 97,96 & 16,415 & 102,412 & 1345,228 & 75,57 & 79,60 & 0.4576 \\
98,41 & 17,272 & 102,171 & 1339,145 & 76,12 & 80,32 & 0.4772 \\
98,85 & 18,083 & 101,930 & 1333,117 & 77,70 & 81,15 & 0.4968 \\
99,30 & 18,854 & 101,688 & 1327,142 & 79,92 & 82,68 & 0.5165 \\
99,74 & 19,589 & 101,447 & 1321,221 & 82,32 & 83,90 & 0.5361 \\
100,19 & 20,292 & 101,206 & 1315,353 & 84,53 & 85,22 & 0.5558 \\
100,63 & 20,966 & 100,965 & 1309,536 & 86,27 & 87,13 & 0.5754 \\
101,08 & 21,615 & 100,724 & 1303,771 & 89,88 & 88,71 & 0.5951 \\
101,52 & 22,240 & 100,482 & 1298,056 & 91,56 & 89,29 & 0.6147 \\
101,97 & 22,844 & 100,241 & 1292,391 & 93,82 & 90,69 & 0.6343 \\
102,41 & 23,428 & 100,000 & 1286,775 & 95,95 & 92,14 & 0.6540 \\
\hline
\end{tabular}

Table 4. Parameters and FEA result values for $\mathrm{m}=10 \mathrm{~mm}$ model

\begin{tabular}{lllllll}
\hline $\begin{array}{l}\text { Contact distance from } \\
\text { the gear 1 center }(\mathrm{mm})\end{array}$ & $\begin{array}{l}\text { Pressure } \\
\text { angle } \alpha^{\mathrm{o}}\end{array}$ & $\begin{array}{l}\text { Contact distance from } \\
\text { the gear 2 center }(\mathrm{mm})\end{array}$ & $\begin{array}{l}\text { Tangential } \\
\text { Load Ft }(\mathrm{N})\end{array}$ & $\begin{array}{l}\text { Equivalent } \\
\text { Stress }\left(\mathrm{N} / \mathrm{mm}^{2}\right)\end{array}$ & $\begin{array}{l}\text { 1st Principal } \\
\text { Stress }\left(\mathrm{N} / \mathrm{mm}^{2}\right)\end{array}$ & $\begin{array}{l}\text { Gear Teeth } \\
\text { height ratio }\end{array}$ \\
\hline 86,45 & 16,960 & 89,91 & 1524,31 & 98,65 & 105,5 & 0.4528 \\
86,80 & 17,693 & 89,56 & 1518,24 & 98,73 & 107,2 & 0.4730 \\
87,14 & 18,392 & 89,22 & 1512,22 & 101,6 & 108,6 & 0.4933 \\
87,49 & 19,061 & 88,87 & 1506,24 & 107,6 & 111,4 & 0.5135 \\
87,84 & 19,704 & 88,53 & 1500,31 & 109,3 & 112,8 & 0.5337 \\
88,18 & 20,322 & 88,18 & 1494,43 & 112,8 & 114,7 & 0.5540 \\
88,53 & 20,917 & 87,84 & 1488,60 & 114,7 & 116,2 & 0.5742 \\
88,87 & 21,493 & 87,49 & 1482,81 & 120,1 & 117,2 & 0.5944 \\
89,22 & 22,050 & 87,14 & 1477,06 & 122,5 & 119,9 & 0.6146 \\
89,56 & 22,590 & 86,80 & 1471,36 & 125,5 & 120,9 & 0.6349 \\
89,91 & 23,113 & 86,45 & 1465,70 & 127,4 & 122,4 & 0.6551 \\
\hline
\end{tabular}

Table 5. $\mathrm{x}$ Displacements versus tooth height ratio

\begin{tabular}{|c|c|c|c|c|c|}
\hline \multicolumn{2}{|l|}{$\mathrm{m}=6 \mathrm{~mm}$} & \multicolumn{2}{|l|}{$\mathrm{m}=8 \mathrm{~mm}$} & \multicolumn{2}{|l|}{$\mathrm{m}=10 \mathrm{~mm}$} \\
\hline $\begin{array}{l}\text { Gear Teeth } \\
\text { height ratio }\end{array}$ & $\begin{array}{l}x \text { Displacement at the } \\
\text { point of contact }(\mathrm{mm})\end{array}$ & $\begin{array}{l}\text { Gear Teeth } \\
\text { height ratio }\end{array}$ & $\begin{array}{l}\mathrm{x} \text { Displacement at the } \\
\text { point of contact }(\mathrm{mm})\end{array}$ & $\begin{array}{l}\text { Gear Teeth } \\
\text { height ratio }\end{array}$ & $\begin{array}{l}x \text { Displacement at the } \\
\text { point of contact }(\mathrm{mm})\end{array}$ \\
\hline 0.4485 & 0,0062 & 0.4576 & 0,0045 & 0.4528 & 0,0043 \\
\hline 0.4700 & 0,0064 & 0.4772 & 0,0046 & 0.4730 & 0,0045 \\
\hline 0.4915 & 0,0067 & 0.4968 & 0,0048 & 0.4933 & 0,0046 \\
\hline 0.5130 & 0,0070 & 0.5165 & 0,0050 & 0.5135 & 0,0049 \\
\hline 0.5345 & 0,0073 & 0.5361 & 0,0052 & 0.5337 & 0,0051 \\
\hline 0.5561 & 0,0077 & 0.5558 & 0,0054 & 0.5540 & 0,0053 \\
\hline 0.5776 & 0,0081 & 0.5754 & 0,0057 & 0.5742 & 0,0055 \\
\hline 0.5991 & 0,0084 & 0.5951 & 0,0059 & 0.5944 & 0,0058 \\
\hline 0.6206 & 0,0088 & 0.6147 & 0,0061 & 0.6146 & 0,0043 \\
\hline 0.6421 & 0,0092 & 0.6343 & 0,0064 & 0.6349 & 0,0045 \\
\hline 0.6636 & 0,0096 & 0.6540 & 0,0045 & 0.6551 & 0,0046 \\
\hline
\end{tabular}


Table $6 . \mathrm{Kx}$ stiffness versus tooth height ratio

\begin{tabular}{|c|c|c|c|c|c|}
\hline \multicolumn{2}{|l|}{$\mathrm{m}=6 \mathrm{~mm}$} & \multicolumn{2}{|l|}{$\mathrm{m}=8 \mathrm{~mm}$} & \multicolumn{2}{|l|}{$\mathrm{m}=10 \mathrm{~mm}$} \\
\hline $\begin{array}{l}\text { Gear Teeth } \\
\text { height ratio }\end{array}$ & $\mathrm{Kx} \mathrm{N} / \mathrm{mm}$ & $\begin{array}{l}\text { Gear Teeth } \\
\text { height ratio }\end{array}$ & $\mathrm{Kx} \mathrm{N} / \mathrm{mm}$ & $\begin{array}{l}\text { Gear Teeth } \\
\text { height ratio }\end{array}$ & $\mathrm{Kx} \mathrm{N} / \mathrm{mm}$ \\
\hline 0,4485 & 300077,3 & 0,4576 & 268695,7 & 0,4528 & 239620,3 \\
\hline 0,47 & 288094 & 0,4772 & 260106,2 & 0,473 & 230847,3 \\
\hline 0,4915 & 276312,9 & 0,4968 & 248801,7 & 0,4933 & 222297,3 \\
\hline 0,513 & 264789,1 & 0,5165 & 239732,9 & 0,5135 & 214470,3 \\
\hline 0,5345 & 253829,7 & 0,5361 & 231208,7 & 0,5337 & 207120,4 \\
\hline 0,5561 & 243165,1 & 0,5558 & 222518,1 & 0,554 & 200450 \\
\hline 0,5776 & 233273,7 & 0,5754 & 215052,9 & 0,5742 & 193890,5 \\
\hline 0,5991 & 223867,2 & 0,5951 & 207588,6 & 0,5944 & 187619,9 \\
\hline 0,6206 & 214536,4 & 0,6147 & 200769,4 & 0,6146 & 181698,8 \\
\hline 0,6421 & 205877,3 & 0,6343 & 194290,1 & 0,6349 & 176027,1 \\
\hline 0,6636 & 197327,2 & 0,654 & 188127,5 & 0,6551 & 170298,5 \\
\hline
\end{tabular}

\section{Bending Deflection Finite Element Analysis}

For bending deflection calculation the $\mathrm{x}$ Displacement at the point of contact values computed for all the single tooth models. Since the loading forces distributed to a mirror four lanes facial area which, as described, the effect of Hertz deflection was diminished, the value of the $\mathrm{x}$ Displacement derived from FEA at the contact point representing the circumference bending deflection with good approximation.

\section{Stiffness Estimation}

Finite element contact between pinion and wheel tooth pairs is not taken into account (Chaari et al., 2009). In order to find the singular stiffness of one tooth of the pinion, we follow the same load analysis as we have already described in chapter Materials and Methods.

In order to find the singular stiffness of one tooth of the pinion, a linear distributed force $F$, which simulates the action of the meshing tooth of the wheel, is applied to the tooth flank normal to the involute profile and along the line of action at the appropriate nodes. This force is introduced by its two projections on $\_x$ axis and $y$ axis. Two deflections $\delta x$ and $\delta y$ are obtained and the deflection of the tooth along the direction of the force is given by:

$\delta=\delta x \cos \left(\alpha_{m}\right)+\delta y \sin \left(\alpha_{m}\right)$

where, $\alpha_{m}$ is the operating pressure angle.

The single stiffness of the tooth is then obtained by:

$K_{x}=F u / \delta x$

Taking into account the data of Table 2-4, we identify single stiffness $K_{x}$ of the tooth, due ratio (17).

\section{Conclusion}

In this study a discrete loading model of gears' teeth was created and analyzed with method with application of FEA software. The mesh load was applied in discrete loading lanes all along the tooth contact surface from the LPSTC to the HPSTC.

From the simulation of three different modul teeth, it eventuates (Table 5 and 6, Fig. 14).

- The root bending stresses

- The bending displacements at the points of contact

Subsequently, evaluating the bending displacements data, the peripherical stiffness of each modeled tooth was calculated.

The outcome results are presented in graphs versus the ratio of the contact point height to the total tooth height. The main conclusion that firstly all the above magnitudes shows linear distribution as the contact point moves from LPSTC to the HPSTC and secontly the bending stress and the deflection are in linearly proportional to gear teeth height ratio.

\section{Author's Contributions}

Antonios D. Tsolakis: Participated in all experiments coordinated the data-analysis.

Konstantinos G. Raptis: Contributed to the writing of the manuscript.

Maria D. Margaritou: Designed the research plan and organized the study.

\section{Ethics}

This article is original and contains unpublished material. The corresponding author confirms that all of the other authors have read and approved the manuscript and no ethical issues involved.

\section{References}

Chaari, F., T. Fakhfakh and M. Haddar, 2009. Analytical modelling of spur gear tooth crack and influence on gearmesh stiffness. Eur. J. Mechan. A/Solids, 28: 461-468.

DOI: $10.1016 / \mathrm{j}$.euromechsol.2008.07.007 
Costopoulos, T. and V. Spitas, 2009. Reduction of gear fillet stresses by using one-sided involute asymmetric teeth. J. Mechan. Mach. Theor., 44: 1524-1534.

DOI: 10.1016/j.mechmachtheory.2008.12.002

DIN 3990, 1987. Calculation of load capacity of cylindrical gears. Deutsches Institut fur Normunh E.V.

Dolan, T.J. and E.L. Broghamer, 1942. A photo-elastic study of stress in Gear tooth fillets. Univ. Ill. Eng. Exp. Sta. Bull.

Fakher, C., F. Tahar and H. Mochamed, 2009. Analytical modelling of spur gear tooth crack and influence on gearmesh stiffness. Eur. J. Mechan., 28: 461-468. DOI: 10.1016/j.euromechsol.2008.07.007

Heywood, R.B., 1962. Designing against Fatigue of Metals. 1st Edn., Reinhold Publishing Corporation, pp: 436 .

ISO 6336:3, 1996. Calculation of the load capacity of spur and helical gears Part 3: Calculationog tooth bending strength.

Kawalec, A., J. Wiktor and D. Ceglarek, 2006. Comparative analysis of tooth-root strength using ISO and AGMA standards in spur and helical gears with FEM-based verification. J. Merch. Des., 128: 1141-1158. DOI: 10.1115/1.2214735

Lewis, W., 1882. Investigation of strenght of gear teeth. Proceedings of the Engineering Club No. 1, (EC' 82), Philadelphia.

Niemann, G., 1982. Machine Elements: Gears. 1st Edn., Springer-Varlag, Berlin, ISBN-10: 3540033785.
Niemann, G., 1960. Maschinelemente II, Band 2. 1st Edn., Springer-Varlag, ISBN-10: 3-540-03378-5, pp: 97.

Raptis, K., T. Costopoulos and A. Tsolakis, 2012. Comparison between Niemann's and finite element method for the estimation of maximum allowable stress of meshing spur gear teeth at highest point of single tooth contact. Am. J. Eng. Applied Sci., 5: 205-216. DOI: 10.3844/ajeassp.2012.205.216

Raptis, K., T. Costopoulos, G. Papadopoulos and A. Tsolakis, 2010. Rating of spur gear strength using photoelasticity and the finite element method. Am. J. Eng. Applied Sci., 3: 222-231. DOI: 10.3844/ajeassp.2010.222.231

Spitas, V. and C. Spitas, 2007. Numerical and experimental comparative study of strengthoptimised AGMA and FZG spur gears. Acta Mech., 193: 113-126. DOI: 10.1007/s00707-006-0384-x

Spitas, V., T. Costopoulos and C. Spitas, 2005. Increasing the strength of standard involute gear teeth with novel circular root fillet design. Am. J. Applied Sci., 2: 1058-1064. DOI: 10.3844/ajassp.2005.1058.1064

Tsolakis, A. and K. Raptis, 2011. Comparison of maximum gear-tooth operating bending stresses derived from niemann's analytical procedure and the finite element method. Am. J. Eng. Applied Sci., 4: 342-346. DOI: 10.3844/ajeassp.2011.350.354 